12. Eliyahu, D., Michalovitz, D., Eliyahu, S., Pinhasi-Kimhi, O. \& Oren, M. Proc. natn. Acad. Sci. U.S.A. 86, 8763-8767 (1989).

13. Mercer, W. F, et al, J. Cell Biochem. 14, 285-290 (1990),

14. Baker, S. J., Markowitz, S., Fearon, E. R., Wilson, J. K. U. \& Vogelstein, B. Science 249, 912-915 (1990)

15. Diller, L. et al. Molec. cell. Biol. 10, 5772-5781 (1990).

16. Michalovitz, D., Halevy, O. \& Oren, M. Cell 62, 671-680 (1990)

17. Martinez, J., Georgoff, l., Martinez, J. \& Levine, A. J. Genes Dev. 5, 151-159 (1991).

18. Chen, P.-L., Chen, Y., Bookstein, R. \& Lee, W.-H. Science 250, 1576-1580 (1990).

19. Mowat, M. A., Cheng, A., Kimura, N., Bernstein, A. \& Benchimol, S. Nature 314, 633-636 (1985).

20. Baker, S. J. et al. Science 244, 217-221 (1989).

21. Nigro, J. M. et al. Nature 342, 705-708 (1989).

22. Vogelstein, B. Nature $348,681-682$ (1990).

23. Takahashi, T. et al. Science 246, 491-494 (1989)

24. Iggo, R., Gatter, K., Bartek, J., Lane, D. \& Harris, A. L. Lancet 335, 675-679 (1990).

25. James, C. D., Carlbom, E., Nordenskjold, M., Collins, V. P. \& Cavanee, W. K. Proc. natn. Acad. Sci. U.S.A. 86, 2858-2862 (1989)

26. Mackay, J., Steel, C. M.., Elder, P. A ., Forrest, A. P. M. \& Evans, H. J. Lancet. ii, 1384-1385 (1988). 27. Kelman, Z. et al. Biood 74, 2318-2324 (1989).

28. Soussi, T., Caron de Fromental, C. \& May, P. Oncogene 5, 945-952 (1990).

28. Soussi, T., Caron de Fromental, C. \& May, P. Oncogent.
29. Malkin, D. et al. Science 250, 1233-1238 (1990).

29. Malkin, D. et al. Science 250, 1233-1238 (1990).
30. Lavigueur, A. et al. Molec. cell. Biol. 9, $3982-3991$ (1989).

31. Hinds, P. W. et al. Cell Growth Different. 1, 571-580 (1990)

32. Halvey, O., Michalovitz, D. \& Oren, M. Science 250, 113-116 (1990).

33. Yewdell, J., Gannon, J. V. \& Lane, D. P. J. Virol. 59, 444-452 (1986).

34. Gannon, J. V. Greaves, R., Iggo, R. \& Lane, D. P. EMBO / 9, 1595-1602 (1990)

35. Raycroft, L., Wu, H. \& Lozano, G. Science 249, 1049-1051 (1990)
36. Fields, S. \& Jang, S. K. Science 249, 1046-1049 (1990)

37. Gannon, J. V. \& Lane, D. P. Nature $349,802-806$ (1991)

38. Ginsberg, D. Michalovitz. D. Ginsberg, D. \& Oren, M. Molec. cell. Biol. (in the press).

39. Labow M. A Baim, S. B Shenk, T \& Levine, A. Molec cell Biol 10, 3343-3356 (1990)

40. Wolf, D., Harris, N. \& Rotter, V. Cell 38, 119-126 (1984).

41. Sarnow, P., Ho, Y. S., Williams, J. \& Levine. A. J. Cell 28, 387-394 (1982).

42. Werness, B. A., Levine, A. J. \& Howley, P. M. Science 248, 76-79 (1990).

43. Whyte, P. et al. Nature 334, 124-129 (1988)

44. DeCaprio, J. A. et al. Cell 54, 275-283 (1988).

45. Dyson, N., Howley, P. M., Munger, K. \& Harlow, E. Science 243, 934-936 (1989).

46. Scheffner, M., Werness, B. A., Huibregtse, J. M., Levine, A. J. \& Howley, P. M. Cell 63, 1129-1136 (1990)

47. Braithwaite, A. W. et al. Nature 329, 458-460 (1987).

48. Gannon, J. V. \& Lane, D. P. Nature 329, 456-458 (1987).

49. Wang, E. H., Friedman, P. N. \& Prives, C. Cell 57, 379-392 (1989)

50. Wilcock, D. \& Lane, D. P. Nature 349, 429-432 (1991).

51. Kern, S. E. et al. Oncogene 6, 131-136 (1991).

52. Scheffner, M., Munger, K., Byrne, J. C. \& Howley, P. M. Proc. natn. Acad. Sci. U.S.A. (in the press)

53. Baker, S. J. et al. Cancer Res. 50, 7717-7722 (1991).

54. Chiba, I. et al. Oncogene 5, 1603-1610 (1990).

55. Prosser, J., Thompson, A. M., Cranston, G. \& Evans, H. J. Oncogene 5, 1573-1579 (1990).

56. Cheng, J. \& Haas, M. Molec. cell. Biol. 10, 5502-5509 (1990).

57. Bartek, J., Iggo, R., Gannon, J. \& Lane, D. Oncogene 5, 893-899 (1990).

58. Rodrigues, N. R. et al. Proc. natn. Acad. Sci. U.S.A. 87, 7555-7559 (1990)

59. Menon, A. C. et al. Proc. natn. Acad. Sci. U.S.A. 87, 5435-5439 (1990).

60. Mulligan, L. M. Matlashewski, G. J, Scrable, H. J. \& Cavenee, W. K. Proc natn. Acad Sci. US A. $87,5863-5867(1990)$

61. Romano. J. W. et al. Oncogene 4, 1483-1488 (1989)

\title{
ARTICLES
}

\section{New use of BCG for recombinant vaccines}

\section{K. Stover, V. F. de la Cruz, T. R. Fuerst, J. E. Burlein, L. A. Benson, L. T. Bennett, G. P. Bansal, J. F. Young, M. H. Lee*, G. F. Hatfull", S. B. Snapper ${ }^{\dagger}$, R. G. Barletta', W. R. Jacobs Jr' \& B. R. Bloom}

Medlmmune Incorporated, Gaithersburg, Maryland 20878, USA

* Division of Biological Sciences, University of Pittsburgh, Pittsburgh, Pennsyivania 15260, USA

† Howard Hughes Medical Institute, Albert Einstein College of Medicine, Bronx, New York 10461, USA

$B C G$, a live attenuated tubercle bacillus, is the most widely used vaccine in the world and is also a useful vaccine vehicle for delivering protective antigens of multiple pathogens. Extrachromosomal and integrative expression vectors carrying the regulatory sequences for major BCG heat-shock proteins have been developed to allow expression of foreign antigens in BCG. These recombinant BCG strains can elicit long-lasting humoral and cellular immune responses to foreign antigens in mice.

VACCINES are the most cost-effective medical intervention known to prevent disease ${ }^{1,2}$. Although two million children's lives are saved each year by immunization ${ }^{3,4}$, it will be very difficult to protect more children in the poorest countries with existing technology. Significant problems inherent in existing vaccines include the need for repeated immunizations, reduced effectiveness due to maternal antibodies in children in the vulnerable first months of life, the need for injection, heat instability and cost. One strategy which might overcome some of these limitations is the development of recombinant vaccine vehicles which allow simultaneous expression of multiple protective antigens of different pathogens.

BCG (bacille Calmette-Guèrin), a live attenuated bovine tubercle bacillus used to immunize against tuberculosis ${ }^{5}$, offers some unique advantages for developing such a multivaccine vehicle: (1) BCG is the most widely used vaccine in the world, having been given to over 2,500 million people since 1948 , with a low incidence of serious complications (case fatality rate of $\left.0.19 / 10^{6}\right)^{6} ;(2)$ it can be given at or any time after birth, and is unaffected by maternal antibodies; (3) BCG is given as a single inoculum and sensitizes to tuberculoproteins for 5-50 years; (4) it is a potent adjuvant in experimental animals and $\operatorname{man}^{7,8} ;(5)$ BCG can be administered as an oral vaccine; (6) it is the most heat stable of live vaccines; and (7) it is inexpensive to produce.

\section{Multicopy and integrating shuttle vectors}

First generation Escherichia coli-mycobacterial shuttle vectors, including temperate phages and plasmids, were used to demonstrate the feasibility of transforming and propagating recombinant DNA in Mycobacterium smegmatis and $\mathrm{BCG}^{9,10}$. We found these first-generation vectors, for example plasmid pYUB12, to be unsuitable for the introduction and expression of foreign genes in mycobacteria because they were large, lacked useful unique restriction sites and, in the absence of antibiotic selection, were unstable in BCG. However, we have now identified a 1.8-kilobase (kb) segment (oriM) from plasmid pAL5000 ${ }^{11}$ which supports plasmid replication in M. smegmatis and BCG. Modification of oriM by polymerase chain reaction (PCR) mutagenesis was done to eliminate undesirable restriction sites and an oriM cassette was then used as the basis for developing second-generation extrachromosomal vectors using three additional PCR cassettes: (1) the E. coli plasmid replicon derived from pUC19 (oriE); (2) the Tn903-derived aph gene conferring kanamycin resistance $\left(\operatorname{kan}^{\mathrm{r}}\right)$ as a selectable marker; (3) an expression cassette containing a mycobacterial promoter, a multiple cloning site and a transcriptional terminator. The resulting $E$. coli-mycobacteria shuttle vector (Fig. 1a) were shown to transform $B C G$ at high efficiencies $\left(10^{5}-10^{6}\right.$ c.f.u. per $\mu \mathrm{g}$ DNA) and maintain about five plasmid copies per genome equivalent (Fig. $1 b$ ).

An advantage of BCG is its innocuous persistence in vivo that could provide continuing immunization to recombinant antigen. However, the vectors carrying antigen genes need to be stably 


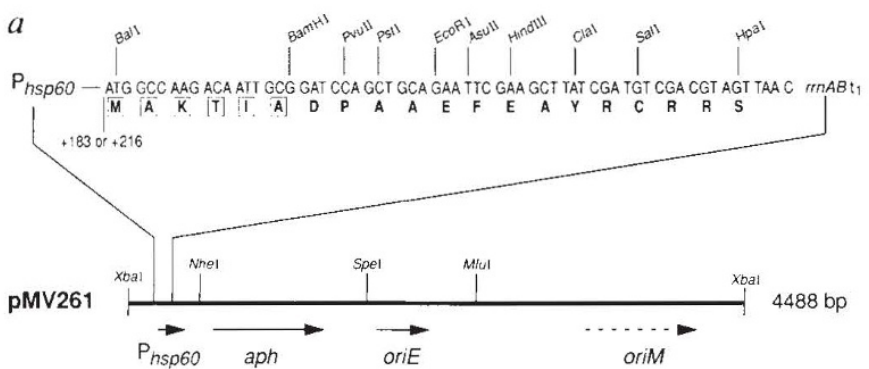

pMV361

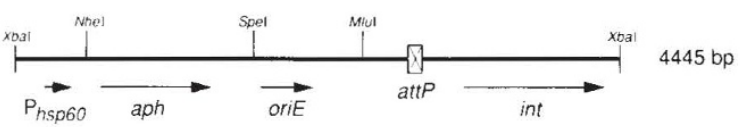

FIG. 1 a, BCG extrachromosomal (pMV261) and integrative (pMV361) expression vectors. Plasmids pMV261 and pMV361 share common elements including an expression cassette, the Tn903-derived aph gene conferring kanamycin-resistance as a selectable marker, and an $E$. coli origin of replication (oriE) derived from pUC19. They differ by the inclusion of either a mycobacterial plasmid origin of replication (oriM) or the attP and int genes of mycobacteriophage L5. The expression cassette contains $404 \mathrm{bp}$ of the 5 ' regulatory region of the BCG $h s p 60$ gene $^{31}$, including the first six amino acids (in boxes, single-letter amino-acid notation), 10 unique cloning sites and the rrnABt1 transcriptional terminator ${ }^{32}$ aligned in the same transcriptional orientation as the other elements. $b$, Comparison of extrachromosomal (pMV261) and integration-proficient (pMV361) vectors. The $E$. coli lacZ gene was cloned into the unique BamHI sites of pMV261 and pMV361 to form fusion proteins with $h s p 60$ and transformed into the Pasteur strain of BCG

maintained in vivo. Selections for maintenance of plasmids in vivo which are useful in other bacterial systems ${ }^{12}$ have not yet been adapted for the mycobacteria and as an alternative approach we have exploited the site-specific integration system of a temperate mycobacteriophag $\mathrm{e}^{13}$. The integration-proficient vector, pMV361, was constructed by replacing the oriM region of pMV261 with a DNA segment carrying the attachment site $($ att $P$ ) and the integrase (int) gene (Fig. 1a) from the mycobacteriophage $\mathrm{L}^{13}$. BCG is transformed with pMV361 through a site-specific integration into the chromosomal attB site with a similar efficiency to that of extrachromosomal vectors. Because the phage xis gene is not present the integrated vectors are stably maintained even without antibiotic selection ${ }^{13}$. Compatibility with oriM-containing plasmids also adds flexibility to these vector systems.

FIG. 2 a, Primer extension analysis of $h s p 60$ transcription. BCG was grown to mid log-phase (Absorbance at $650 \mathrm{~nm}$, 0.44) in Dubos broth (Difco) supplemented with albumin dextrose complex (D-ADC broth) at $37^{\circ} \mathrm{C}$ then rapidly shifted to $45^{\circ} \mathrm{C}$. Total RNA was extracted from culture aliquots taken at $0,5,30,60,120$, and $180 \mathrm{~min}$ after heat-shock and subjected to primer extension ${ }^{33}$ using the 5'-CTGCCACTCGCTGCGACG-3'. Two transcription start sites were identified for the BCG $h s p 60$ gene at positions 183 and $216 \mathrm{bp}$ (arrows) upstream of the ATG translational start site of $h s p 60$ protein. As shown, messenger RNA originating at the two transcription start sites markedly increased with heat shock, but differed with respect to both the presence of $\mathrm{mRNA}$ at $37^{\circ} \mathrm{C}$ and the maintenance of the elevated level at $45^{\circ} \mathrm{C}$. $b, \beta$-galactosidase expression by extrachromosomal and integrative BCG recombinants. BCG containing pMV261::lacZ or pMV361::lacZ cultures were grown to mid log-phase at $37^{\circ} \mathrm{C}$ and each was divided into four aliquots. Three samples from each culture were incubated at $37^{\circ} \mathrm{C}$ for an additional $30 \mathrm{~min}$, with two of the samples being subjected to stress by the adjustment to $0.002 \% \mathrm{H}_{2} \mathrm{O}_{2}$ or $\mathrm{pH} 5$ with the addition of $\mathrm{H}_{2} \mathrm{PO}_{4}$. Another sample from each set was stressed by incubation at $45^{\circ} \mathrm{C}$ and incubated for an additional 30 min at either $45^{\circ} \mathrm{C}$ or $37{ }^{\circ} \mathrm{C}$ and adding $\mathrm{H}_{2} \mathrm{O}_{2}$ or $\mathrm{H}_{2} \mathrm{PO}_{4}$. Cells were collected and sonicated, and the lysates were subjected to $4-15 \%$

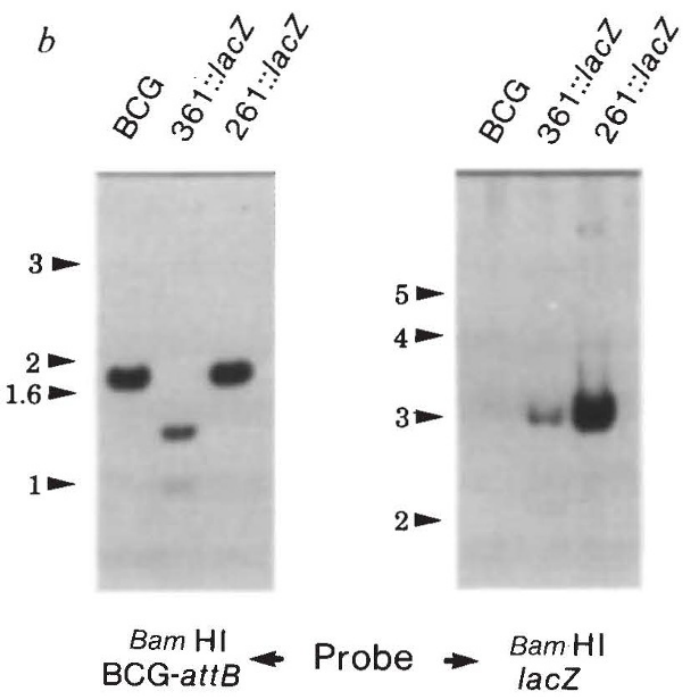

as described previously ${ }^{10}$. Chromosomal DNAs were isolated from BCG and BCG transformants, digested with $B a m H I$, and Southern blot analyses were performed probing with either the BCG attB (ref. 13) gene or lacZ. Probing with attB (left panel) demonstrates that the pMV361::lacZ is integrated into the BCG chromosome as seen by the resolution of the attB sequence into an attL and attR fragments. Probing with the lacZ gene (right panel) demonstrates that pMV261: lac $Z$ has a copy number of five as quantitated by an AMbis Direct Radioactivity Detector relative to the pMV361::lacZ site-specific integrant.

\section{Foreign antigen expression in BCG}

Although little is known about mycobacterial gene expression, particularly in the intracellular environment of the host, the abundant and highly conserved $h s p 60$ and $h s p 70$ cognate stress proteins are major antigens of mycobacteria, rickettsia, coxiella and chlamydia ${ }^{14-18}$. The Hsp60 and Hsp70 proteins are essential under all growth conditions, but are expressed at higher amounts in response to stress ${ }^{19}$. Thus the regulatory sequences of the BCG $h s p 60$ and $h s p 70$ genes were chosen to drive the expression of foreign antigen genes in BCG. Primer extension analysis identified two shock-responsive transcription start sites for the hsp60 (Fig. 2a) and hsp70 (data not shown) genes which had not been characterized previously. Endogenous BCG Hsp60 and Hsp70 protein levels also increased in response to stress with heat and acid but not peroxide (Fig. $2 b$ ).

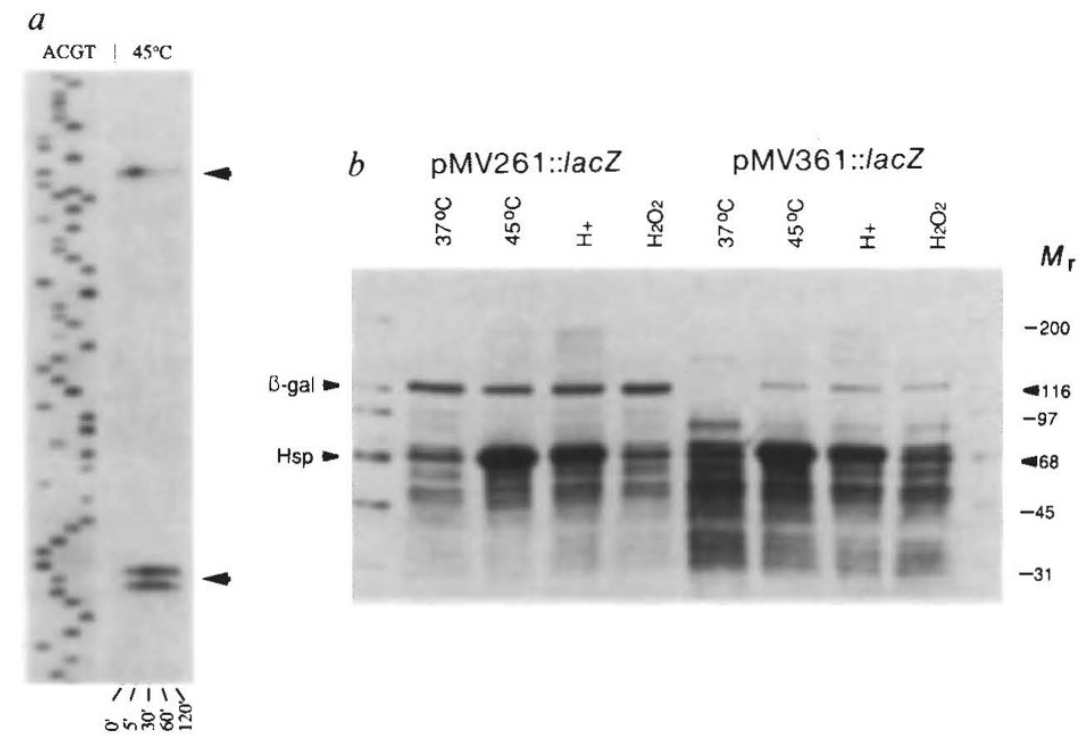

gradient SDS-PAGE, fixed and stained with Coomassie blue. Numbers in right margin denote relative molecular mass $\left(M_{r}\right.$ in $\left.\mathrm{kDa}\right)$. Arrows, $\beta$-gal and the $h s p 60-h s p 70$ doublet at about 65 and $71 \mathrm{kDa}$, respectively. 


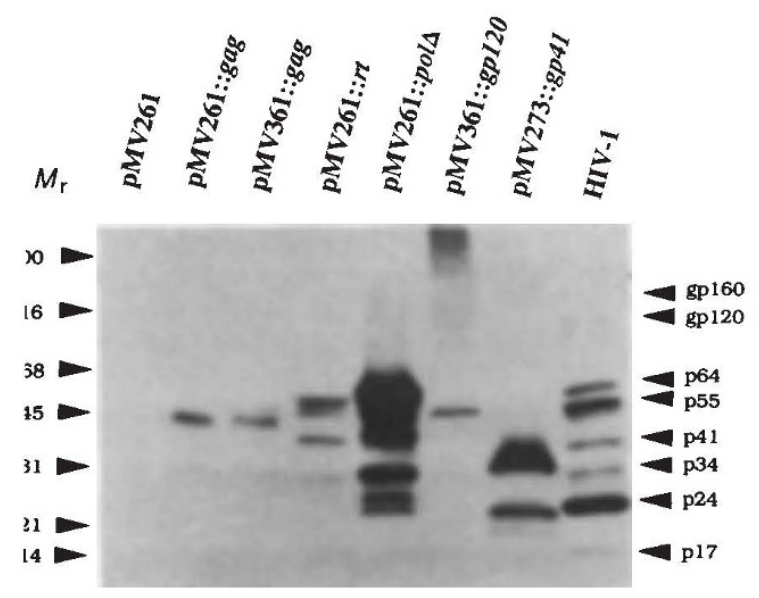

FIG. 3 Expression of HIV-1 antigens (IIIB isolate) in recombinant BCG. Genes encoding HIV-1 gag, $r$ t (reverse transcriptase), pols (polymerase minus protease), gp120, and gp41 proteins were amplified by PCR, fused to the sixth codon of the $h s p 60$ gene in pMV261 or pMV361, or the HSP70 gene ${ }^{37}$ in PMV273 and transformed into BCG. Lysates of recombinant BCG were analysed for expression by western blot analysis of $4-20 \%$ gradient SDSPAGE using human sera from a patient infected with HIV -1 and ${ }^{125}$ I-labelled Staphylococcus aureus protein A. Arrows in left margin denote $M_{\mathrm{r}}$ standards. Arrows in right margin indicate apparent $M_{\mathrm{r}}$ (in $\mathrm{kDa}$ ) of HIV-1 proteins.

The E. coli lacZ genes was placed under control of the BCG $h s p 60$ regulatory sequences to evaluate its potential for expressing foreign genes. Striking constitutive expression of the $h s p 60$ driven lac $Z$ gene, in excess of $10 \%$ of total BCG protein, was observed from the extrachromosomal vector (Fig. $2 b$, pMV261::lacZ). Expression of $h s p 60:$ lac $Z$ from the integrative vector was lower than that from the extrachromosomal vector; however, expression from the integrative vector, in contrast to the expression from the extrachromosomal vector, showed a coincident increase in Hsp60- $\beta$-gal in response to stress with heat, acid, and peroxide (Fig. $2 b$ ).

Antigen genes from a variety of pathogens including viral, parasitic and bacterial pathogens were cloned and expressed in recombinant BCG ( $\mathrm{rBCG}$ ). Several of the antigens of human immunodeficiency virus type 1 (HIV-1), which are relatively difficult to express at high amounts in other bacterial systems, were expressed in rBCG. Although expression of the HIV-1 pol coding region (minus protease) was substantial, expression quantities for most of the $h$ sp60-driven HIV-1 antigen genes did not rival those of $h s p 60-\beta$-gal (Fig. 3). Extrachromosomal expression sometimes appeared to be lethal and it was only possible to express foreign genes in the single-copy integrative vectors (for example HIV-1 gp120). In other cases extrachromosomal and integrative expression were comparable (for example HIV-1 gag, Fig. 3). These studies establish the value of the BCG $h s p$ regulatory sequences in driving expression of foreign genes in mycobacteria and suggest that homologous $h s p$ sequences may be generally useful for enhancing expression of foreign genes in other recombinant vaccines.

\section{Immune responses to model antigens}

To investigate the immunological capabilities and possible limitations of $\mathrm{rBCG}$ vaccines, we examined the humoral and cellular immune responses to several antigens expressed in BCG. Mice $(\mathrm{BALB} / \mathrm{c})$ were immunized with a $\mathrm{rBCG}$ expressing $\beta$-gal on a plasmid as a fusion protein with the first six amino acids of BCG $h s p 60$ antigen. Antibodies to $\beta$-gal were found in mice inoculated with the rBCG by all routes (Fig. $4 a$ ). Most striking was that very low numbers of live rBCG (as few as 200 c.f.u. given intravenously, and $10^{4}$ c.f.u. intradermally) were sufficient for high levels of antibody to $\beta$-gal (Fig. $4 a$ ). After a delay, antibody levels were sustained for many weeks. Antibodies to $\beta$-gal were not only higher (ELISA titre of $1: 30,000$, Fig. $4 a$ ) than responses to $\mathrm{BCG}$ sonicate (titre $1: 5,000$ ), but persisted much longer than those to BCG, which peaked only $2-4$ weeks after immunization and waned thereafter. Thus greater antibody responses may be achieved to recombinant proteins expressed by $\mathrm{rBCG}$ than to antigens of BCG itself.

The growth of $\mathrm{rBCG}$ and the stability of the extrachromosomal plasmid without in vivo drug selection were established by the recovery of $\mathrm{rBCG}$ from mouse spleens 2-4 weeks after immunization. All BCG colonies were $\operatorname{kan}^{\mathrm{r}}$ and expressed $\beta$-gal, and the number of bacilli recovered was $>30$ times that estimated to be localized in the spleen from the original inoculum. Viable $\mathrm{rBCG}$ recovered from spleen diminished between 2 and 4 weeks which is similar to non-recombinant $\mathrm{BCG}$, but all $\mathrm{rBCG}$ recovered remained $\operatorname{kan}^{\mathrm{r}}$ and expressed $\beta$-gal. These results, coupled with the delayed but sustained anti- $\beta$-gal antibody responses, establish that $h s p 60$-driven expression of lac $Z$ was effective for the expression of this model antigen in vivo, and suggest that actively growing $\mathrm{rBCG}$ can provide continuous boosting to the foreign antigen from a single immunization.

To assess the humoral immune response to an antigen expressed at substantially lower levels than $\beta$-gal in BCG, mice
FIG. 4 a, Antibody production to $\beta$-galactosidase in mice immunized with rBCG: : lacZ. The rBCG was grown to mid log-phase in Dubos-ADC broth, then concentrated 20 -fold by centrifugation. The concentrated bacteria were resuspended in PBS + $0.05 \%$ Tween 80 and cup sonicated briefly to disperse clumped bacteria. Six-week-old BALB/C mice were inoculated with a single dose of $2 \times 10^{2}$, $2 \times 10^{4}$ or $2 \times 10^{6}$ c.f.u. (determined after inoculation in each experiment) by either intravenous (i.v.), intradermal (i.d.), or intraperitoneal (i.p.) routes. Sera were obtained biweekly, pooled and analysed

by a $\beta$-gal-specific enzyme-linked immunosorbant assay (ELISA) with horse radish peroxidase-conjugated goat anti-mouse immunoglobulin and ABTS colour developing reagent (Kirkegaard and Perry). Colour reactions were read kinetically over $3 \mathrm{~min}$ on a $V_{\max }$ (maximum reaction velocity) plate reader (Molecular Devices) and results are presented as $V_{\max }$ rates (mOD $\left.\mathrm{min}^{-1}\right) . V_{\max }$ rates of $200 \mathrm{mOD} \mathrm{min}^{-1}$ and $300 \mathrm{mOD} \mathrm{min}^{-1}$ were equivalent to standard ELISA titre determinations of about $1: 10,000$ and 1:30,000, respectively. $\square, 10^{6}$ i.v.; $\bigcirc, 10^{6}$ i.p.; $\triangle, 10^{4}$ i.d.;, $10^{2}$ i.v.; $\square$, naive. $b$, Antibody production to tetanus toxin fragment $C$ in mice immunized with rBCG: : toxC. DNA encoding fragment $\mathrm{C}$ of Clostridium tetani toxin (tox $C$ ) was cloned and fused in frame with the sixth codon of BCG $h s p 60$ into pMV261. NIH swiss mice were inoculated with predetermined c.f.u. by the
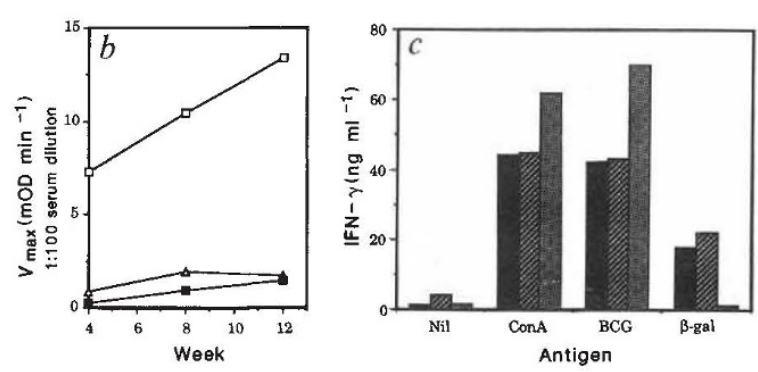

indicated routes. Parallel inoculations were made with the same preparations that had been heat killed for $30 \mathrm{~min}$ at $70^{\circ} \mathrm{C}$. Sera were obtained monthly, pooled and analysed at 1:100 dilution by ELISA as above using plates coated with $10 \mu \mathrm{g} \mathrm{ml}^{-1}$ tetanus toxoid (Connaught Labs). $\square$, Live $10^{6}$ i.d.; $\triangle$, dead $10^{6}$ i.d.; $\square$, naive. $c$, INF- $\gamma$ production by lymphocytes from mice immunized with rBCG: : lacZ and rBCG: :gp120, Splenocytes (ACK-treated $5 \times 10^{6} \mathrm{ml}^{-1}$, where $\mathrm{ACK}$ is ammonium chloride/potassium carbonate) were cultured in $0.5 \mathrm{ml} \mathrm{50 \%} \mathrm{RPMI} 1640$ medium, 50\% EHAA medium (Gibco), 10\% FCS supplemented with: media (Nil); concanavalin A, $5 \mu \mathrm{g} \mathrm{ml}^{-1}$; WHO BCG Vaccine, $100 \mu \mathrm{l} \mathrm{ml} l^{-1}$ culture; or $\beta$-galactosidase, $10 \mu \mathrm{g} \mathrm{ml}^{-1}$. IFN- $\gamma$ levels in supernates from $72 \mathrm{~h}$ cultures were determined by ELISA ${ }^{34}$. Solid bars, $10^{2}$ rBCG lac (i.v.); hatched bars, $10^{6}$ rBCG: : lacZ (i.p.); dotted bars, rBCG: :gp 120 (i.p.). 
were immunized with rBCG expressing the fragment $\mathrm{C}$ (ToxC) of tetanus toxin ${ }^{20}$. This fragment (relative molecular mass, $50,000)$ lacks toxic activity, but binds to the cellular glycolipid receptor. ToxC expression was $1 / 250$ th that of $\beta$-gal on a weight basis (1/100 on a molar basis). Immunization with a single dose of $\mathrm{rBCG}:$ : tox $C$ led to antibody levels that increased for at least 12 weeks (Fig. $4 b$ ). The ability of rBCG to induce antibodies is therefore not unique to $\beta$-gal or to antigens expressed only at high levels. Heat-killed BCG::toxC was not effective at immunization, supporting the view that the persisting immune responses with $\mathrm{rBCG}$ are due to growth and persistence of the vaccine. That $\mathrm{IgG}$ responses were obtained implies that $\mathrm{T}$ cells also responded to the rBCG. This was confirmed by assessment of cellular immune responses. Lymphokines, specifically interferon- $\gamma$ (IFN- $\gamma$ ), were produced in vitro by spleen cells stimulated with $\beta$-gal obtained only from animals inoculated with rBCG::lacZ, and not with rBCG::gp120, (Fig. $4 b$ ).

Cytotoxic $\mathrm{T}$ lymphocytes (CTL) are critical for resistance to many viral and bacterial infections ${ }^{21}$. There was much cytotoxic activity in splenocytes from mice immunized with $2 \times 10^{6}$, or as few as 200 c.f.u. rBCG: : lac $Z$ given 19 weeks earlier (Fig. $5 a-c$ ). To learn whether the induction of CTL precursors is likely to be a general property of $\mathrm{rBCG}$ vaccines or whether it is peculiar only to $\beta$-gal or to antigens expressed at very high levels, lymphocytes from mice immunized with rBCG expressing HIV-1 gp120 antigen from pMV361 were examined for cytotoxic activity against P815 target cells pulsed with the P18 peptide. This peptide is the major CTL epitope of HIV gp120 in BALB/c mice and killing has been shown to be restricted to the major histocompatibility complex (MHC) class I D $\mathrm{D}^{\mathrm{d}}$ allele $\mathrm{e}^{22}$. There was notable specific lysis (Fig. $5 d$ ), confirming the induction of CTL to the gp120 peptide. The failure to detect killing of the target cells in the absence of the peptide and the fact that our P815 cells did not express MHC class II antigens, suggest that lysis is mediated by MHC class I-restricted CTL.

\section{Discussion}

The ultimate goal in the development of vaccines is to induce sustained immunity against multiple pathogens with the minimum number of inoculations. Whether any single vehicle or delivery system can effectively evoke the required immune responses to a wide variety of antigens in a single dose remains to be seen. Nevertheless, it has been possible to express, in addition to the three antigens described here, antigens from 17 viral, bacterial and parasitic pathogens in $r B C G$. All the immunological data presented here derive from single-dose immunizations. Although notable amounts of antibodies were produced and maintained to both $\beta$-gal and to ToxC, the lack of significant titres ( $>1: 100$ dilution) of antibodies found to HIV gp120 suggests that the level of expression may be important. In the case of both $\beta$-gal and ToxC, antibodies were induced by the intradermal route used for human immunization. It is not evident how an intracellular organism whose recombinant protein would presumably be subjected to proteolysis within the lysosomal compartment of macrophages, can effectively elicit antibody responses, which generally recognize epitopes on intact antigens. Because under standard conditions for culture of BCG vaccine substrains only $25-40 \%$ of acid-fast bacilli are able to form colonies ${ }^{23}$, the $\mathrm{rBCG}$ vaccines must contain nonviable organisms capable of releasing relatively intact recombinant antigens recognized by B cells. Nevertheless, killed $\mathrm{rBCG}$ expressing ToxC failed to immunize, indicating that dead bacilli are not effective immunogens. This result and the finding that $\mathrm{rBCG}$ expressing $\beta$-gal have been isolated at least 4 weeks after immunization, support our interpretation that the continuing production of antibodies is due to antigen molecules being released from the rBCG over long periods of time in vivo.

Because mycobacteria are rapidly phagocytosed and contained within the endosomal compartment of phagocytic cells $^{24,25}$, it was not unexpected that $\mathrm{rBCG}$ would be an effective vehicle for inducing both $T$-helper cells capable of inducing B-cell production of IgG antibodies and the T cells capable of secreting lymphokines such as IFN- $\gamma$ (Fig. $4 b$ ). It was not obvious, however, that it would be effective in stimulating cytotoxic T lymphocytes. That BCG can generate CTL restricted by $\mathrm{MHC}$ class I in mice ${ }^{26,27}$ encouraged us to assay for cytotoxic activity in animals immunized with $\mathrm{rBCG}$. CTL were generated to both $\beta$-gal and HIV-1 gp 120 (Fig. 5). There are two possible interpretations: some $\mathrm{rBCG}$ may escape from lysosomes and penetrate into the cytoplasmic compartment; or because the general examples of antigen processing come mainly from studies of antigens that persist for only short times in antigenpresenting cells, conceivably antigens produced by $\mathrm{rBCG}$ persisting for long times in the endosomal compartment can be selected and presented to T cells both by MHC class I and class II antigens.

Although the immune responses obtained to recombinant antigens expressed in $\mathrm{BCG}$ reported here are encouraging, much remains to be learned before $r B C G$ can be perfected as a multivaccine vehicle. Conditions may have to be adjusted to allow optimal expression of different antigens. For some it may be important to include signal sequences that enable recombinant proteins to be secreted intact from the rBCG. New formulations for maximizing the effectiveness of $\mathrm{rBCG}$ given as an oral vaccine remain to be developed. A major challenge will
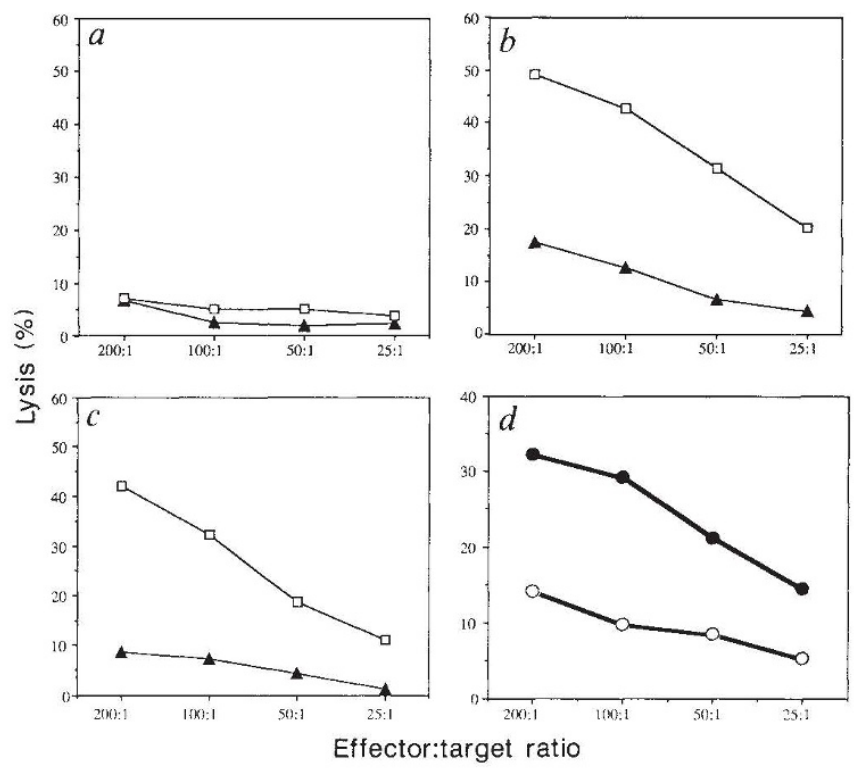

FIG. 5 Cytotoxic T-lymphocyte responses to recombinant antigens expressed in rBCG. $a-c$, Specific cytotoxicity to target cells expressing $\beta$-galactosidase. $\mathrm{BALB} / \mathrm{c}$ mice were immunized as indicated. Splenocytes (ACK-treated, $5 \times$ $10^{6} \mathrm{ml}^{-1}$ ) were stimulated in vitro in $10 \mathrm{ml}$ in upright T25 flasks by coculture for 5 days with mitomycin $\mathrm{C}$-treated cells transfected with the lacZ gene $(\mathrm{C} 3-4 \text { cells })^{35}\left(5 \times 10^{5} \mathrm{ml}^{-1}\right)$. Then a $4 \mathrm{~h}^{51} \mathrm{Cr}$-release assay was done using P815 ( $\mathbf{\Lambda}$ ) and P13.1 cells ${ }^{36}$ (P815 cells transfected with the lacZ gene) ( $\square$ ) as targets. Effector:target ratios are as indicated using 5,000 targets per well. Specific lysis was calculated as follows: $\%$ specific lysis $=100 \times$ (release by effector cells - spontaneous release)/(maximal release-spontaneous release). Spontaneous release in the absence of effector cells was less than $20 \%$ of maximal release by $10 \%$ SDS in all cases. $a, \beta$-gal-IFA ( $10 \mu g$ i.p.); $b$, rBCG: : $\operatorname{lac} Z\left(2 \times 10^{6}\right.$ c.f.u. i.p.); $c$, rBCG: : /acZ $\left(2 \times 10^{2}\right.$ c.f.u. i.v.). $d$, Specific cytotoxicity to the HIV-1 envelope immunodominant CTL epitope (P18 peptide). BALB/c mice were immunized with $10^{6}$ c.f.u. rBCG containing the integrating vector expressing gp 120 (pMV361: :gp 120). Splenocytes were cocultured as above with mitomycin C-treated P815 cells $\left(5 \times 10^{5} \mathrm{ml}^{-1}\right)$ that were pulsed with $250 \mu \mathrm{g} \mathrm{ml}^{-1}$ of $\mathrm{P} 18$ peptide for $1 \mathrm{~h}$. After incubation for 5 days, cells were assayed for killing by $4 \mathrm{~h}^{51} \mathrm{Cr}$-release as above using P815 targets with (O) or without $(\bigcirc)$ pulsing for $1 \mathrm{~h}$ with $250 \mu \mathrm{g} \mathrm{ml}^{-1} \mathrm{P} 18$ peptide. 
be to immunize against antigens, particularly viral antigens, whose protective epitopes require conformations or modification, such as glycosylation and assembly, that cannot be acquired in most procaryotes. There is a precedent in viral systems, however, that priming for immunological memory at the level of the T-helper cell, as by immunization with influenza virus internal antigens, is sufficient to allow induction of accelerated antibody responses to the surface antigens upon infection with virus ${ }^{28-30}$. Thus, even if viral antigens expressed in $\mathrm{rBCG}$ fail to induce virus-neutralizing antibodies, immunological

Received 2 January; accepted 24 April 1991.

1. Walsh, J. A. in Strategies for Primary Health Care (eds Warren, K. S. \& Walsh, J. A.) 1-13 (University of Chicago Press, 1986)

2. Bloom, B. R. Nature 342, 115-120 (1989)

3. State of the World's Children (UNICEF, Oxford, 1990)

4. Henderson, R. H. in Biomedical Science and the Third World: Under the Volcano (eds Bloom, B. R. \& Cerami, A.) 45-68 (New York Academy of Science, 1989).

5. Calmette, A. La Vaccination Preventive contre la Tuberculose par BCG (Masson, Paris, 1927).

6. Lotte, et al. Bull. Int. Union against TB and Lung Dis. 63, 47-59 (1988).

7. Convit, et at. int. J. Lepr. 50, 514-523 (1982)

8. Convit, J. et al. Lancet I, 401-404 (1987).

9. Jacobs, W. R. Jr. Tuckman. M. \& Blom, B. N. Nature 327, 532-536 (1987)

10. Snapper, S. B et al Proc natn Acad Sci. U.S.A. 85, 6987-6991 (1988).

11. Rauzier, J., Moniz-Pereira, J. \& Giquel-Sanzey, B. Gene 71, 315-321 (1988).

12. Curtiss, R. III, Nakayama, K. \& Kelly, S. M. Immunol. Invest. 18, 583-596 (1989).

13. Pascopella, L., Jacobs, W. R. Jr \& Hatfull, G. F. Proc. natn. Acad. Sci. U.S.A. 88, 3111-3115 (1991).

14. Young, D. B., Lathigra, R., Hendrix, R., Sweetzer, D. \& Young, R. A. Proc. natn, Acad, Sci. U.S.A. 85, 4267-4270 (1988)

15. Young, R. A. A. Rev. Immun. 8, 401-420 (1990).

16. Stover, C. K., Marana, D. P., Dasch, G. A. \& Oaks, E. V. Infect. Immun. 58, 1360-1368 (1990).

17. Vockin, M. H. \& Williams, J. C. J. Bact. 170, 1227-1234 (1988).

18. Cerrone, M. C., Jeffrey, J. M. \& Stevens, R. S. Infect. Immun., 59, 79-90 (1991)

19. Buchmeier, N. A. \& Heffron, F. Science 248, 730-732 (1991)

20. Haipern, J. L., Habig, W. H., Neale, E. A. \& Stibitz, S. Infect. Immun. 58, 1004-1009 (1990).

21. Kaufmann, S. H. E. Immun. Today 9, 168-169 (1988).

22. Takahashi, H., Germain. R. N.. Moss, B. \& Berzofsky, J. B. J. exp. Med. 171, 571-576 (1990). memory may be generated such that an efficient secondary response would be obtained following natural infection by virus. This would be particularly important as BCG, which is unaffected by maternal antibodies, can be given earlier in life than most viral vaccines. The hope would be that T-cell memory can ensure protection against severe morbidity and death. We believe these results establish the molecular and immunological foundation for a novel live-vaccine vehicle that may prove useful in stimulating both humoral and cellular immune responses to a wide variety of viral, bacterial and protozoal antigens.

23. Milstien J B. \& Gibson, J. Quality Control of BCG Vaccines by the World Health Organization A Review of Factors that May Influence Vaccine Effectiveness and Safety. (WHO Document WHO/EPI/Gen/89.3, 1989).

24. Hart, P. D'A. \& Armstrong, J. A. Infect. Immun. 10, 742-746 (1974).

25. Armstrong, J. A. \& Hart, P. D'A. J. exp. Med. 142, 1-16 (1975).

26. Muller, I., Cobbold, S. P., Waidmann, H. \& Kaufmann, S. H. E. Infect. Immun. 55, 2037-2041 (1987)

27. Delibero G. Flesh, I. \& Kaufmann S. H. E. Eur J Immun. 18, 59-66 (1988).

28. Russell, S. M. \& Liew, F. Y. Nature 280, 147-149 (1979)

29. Lamb, J. R., Woody, J. N., Hartzman, R. J. \& Eckels, D. D. J. Immun. 129, 1465-1470 (1982)

30. Scherle. P. A. \& Gerhard, W. J. exp. Med. 164, 1114-1128 (1986).

31. Thole, J. E. R. et al. infect. Immun. 55, 1466-1475 (1987).

32. Sarmientos, P., Sylvester, J. E., Contente, S. \& Cashel, M. Cell 32, 1337-1346 (1983).

33. Ausubel, F. M. et al. Curr. Protocols molec. Biol. Sections 4.4 .1 and 4.8 .1 (Green. 1987).

34. Curry, R. C., Keiner, P. A. \& Spitalny, G. L. J. immunol. Meth. 104, 137-142 (1987).

35. Ramensee, H. G., Schild, H. \& Theopold, U. Immunogenetics 30, 296-302 (1989).

36. Carbone, F. R. \& Bevan, M. J. J. exp. Med. 171, 377-387 (1990)

37. Lathigra, R. et al. Molec. Microbiol. (in the press).

ACKNOWLEDGEMENTS. We acknowiedge that $V F$ de la $C$. and CKS made equal contributions to this work. We thank N. Connell and K. Ganjam for plasmid constructs, F. Carbone for the P13.1 cell line, H.-G. Rammensee for the C3-4 cell line, S. Koenig, E. Pearce, A. Sher and R. Davis for advice and comments and S. R. Palaszynski, P. Jalipali and A. Ruiz for technical assistance. This work was supported by the NIH, the Rockefeller Foundation, the UNDP/World Bank/WHO Special Programme for Research and Training in Tropical Diseases Research (IMMLEP) and the WHO/UNDP Programme for Vaccine Development (IMMTUB).

\section{LETTERS TO NATURE}

\section{Giant tunnelling anisotropy in the high- $T_{c}$ superconductor $\mathrm{Bi}_{2} \mathrm{Sr}_{2} \mathrm{CaCu}_{2} \mathrm{O}_{8}$}

\section{Mandrus, L. Forro*, D. Koller \& L. Mihaly}

Department of Physics, State University of New York at Stony Brook, Stony Brook, New York 11794-3800, USA

TUNNELLING spectroscopy has been one of the most fruitful methods in the study of superconductors ${ }^{1,2}$. Excellent agreement has been obtained between theory and experiment, and even the fine details of the tunnelling spectra for conventional, low-transition-temperature (low- $T_{\mathrm{c}}$ ) superconductors have been explained in terms of electron-phonon interactions. The low- $T_{c}$ materials are generally isotropic enough for accurate measurements to be made on polycrystalline specimens; in contrast, it has been difficult to obtain reliable and reproducible tunnelling data for the highly anisotropic high- $T_{\mathrm{c}}$ materials ${ }^{3}$. We have overcome these difficulties by performing break-junction tunnelling measurements ${ }^{4}$ on extremely thin single crystals, and show here that the tunnelling spectra of $\mathrm{Bi}_{2} \mathrm{Sr}_{2} \mathrm{CaCu}_{2} \mathrm{O}_{8}$ are indeed highly anisotropic. In the superconducting state, for electrons tunnelling parallel to the copper oxide planes, there are no electronic states at the Fermi level. In the normal state the tunnelling conductance is nearly independent of the d.c. bias voltage. Tunnelling perpendicular to the copper oxide planes was found to be qualitatively different from that parallel to the planes, and we suggest that electron scattering processes play an important role here.

\footnotetext{
* Permanent address: Institute of Physics of the University, 41001 Zagreb, Yugoslavia.
}

In its most ideal realization, an electron tunnelling measurement provides us with the electronic density of states (DOS) ${ }^{1}$. In particular, for a superconductor-insulator-superconductor junction, one can directly measure the energy gap $2 \Delta$ by observing a sudden increase of conductivity at bias voltages, $V$, exceeding $2 \Delta / e$ (here $e$ is the electron charge). The bias-voltagedependent tunnelling conductance (the 'tunnelling spectrum') is related to the energy-dependent DOS by a simple integral ${ }^{1}$. At low temperatures the conductivity of the junction is close to zero for $V<2 \Delta / e$, indicating zero DOS. For most of the low- $T_{\mathrm{c}}$ superconductors the experiments are very well described by BCS theory ${ }^{5}$. The copper-oxide-based high- $T_{\mathrm{c}}$ superconductors, however, did not exhibit the expected zero conductance ${ }^{5,7}$. One is forced to assume either that BCS theory is not valid for these materials, or that the electron transport cannot be described as an ideal tunnelling process. Is it possible, for example, that the tunnelling is strongly influenced by inelastic electron scattering? Complex tunnelling conductance curves and 'zero-bias anomalies' have been seen in junctions with magnetic impurities ${ }^{8-13}$. The well known structural anisotropy of the copper-oxide-based high- $T_{\mathrm{c}}$ superconductors may also result in nontrivial effects. The tunnelling process is inherently anisotropic, because the particles with non-perpendicular incidence angle are less likely to travel through the potential barrier. What happens if the Fermi surface of the material is so anisotropic that there are no electron momenta perpendicular to the junction surface?

We attempted to answer these questions by performing tunnelling measurements on break junctions ${ }^{4}$ fabricated at low temperature, in vacuum. By using ultra-thin single crystals of $\mathrm{Bi}_{2} \mathrm{Sr}_{2} \mathrm{CaCu}_{2} \mathrm{O}_{8}$, we were able to obtain reproducible superconductor-insulator-superconductor tunnelling spectra in high- $T_{\mathrm{c}}$ superconductors. We found that parallel and perpendicular to 